\title{
Comparative genotyping and phenotyping of Aspergillus fumigatus isolates from humans, dogs and the environment
}

Ivan D. Valdes ${ }^{1 *}$ (D) Joris van den Berg ${ }^{1}$, Annika Haagsman², Natalia Escobar ${ }^{1}$, Jacques F. Meis ${ }^{3,4}$, Ferry Hagen ${ }^{5}$, Pieter Jan Haas ${ }^{6}$, Jos Houbraken ${ }^{5}$, Han A. B. Wösten ${ }^{1}$ and Hans de Cock ${ }^{1}$

\begin{abstract}
Background: Aspergillus fumigatus is a ubiquitous saprotrophic fungus and an opportunistic pathogen of humans and animals. Humans and animals can inhale hundreds of A. fumigatus spores daily. Normally this is harmless for humans, but in case of immunodeficiency, invasive pulmonary aspergillosis (IPA) can develop with a high mortality rate. A. fumigatus also causes non-invasive mycoses like sino-nasal aspergillosis (SNA) in dogs.

Results: In this study we compared A. fumigatus isolates from humans with suspected IPA, dogs with SNA, and a set of environmental isolates. Phylogenetic inference based on calmodulin (CaM) and beta-tubulin (benA) sequences did not reveal A. fumigatus sub-groups linked to the origin of the isolates. Genotyping and microsatellite analysis showed that each dog was infected by one A. fumigatus genotype, whereas human patients had mixed infections. Azole resistance was determined by antifungal susceptibility testing and sequencing of the cyp51A gene. A total of 12 out of 29 human isolates and 1 out of 27 environmental isolates were azole resistant. Of the azole resistant strains, 11 human isolates showed TR $\mathrm{T}_{34} / \mathrm{L} 98 \mathrm{H}(n=6)$ or TR46/Y121 F/T289A $(n=5)$. Phenotypically, isolates from dogs were more variable in growth speed and morphology when compared to those isolated from human and the environment.
\end{abstract}

\section{Conclusions:}

1. A. fumigatus from dogs with SNA are phenotypically very diverse in contrast to their environmental and human counterparts.

2. Phenotypic variability can be induced during the chronic infection process in the sinus of the dogs. The basis of this heterogeneity might be due to genomic differences and/or epigenetic variations.

3. Differences in dogs is a could be a result of within-host adaption and might be triggered by environmental factors in the sinus, however this hypothesis still needs to be tested.

\section{Background}

Aspergillus fumigatus is a filamentous saprotrophic ascomycete that occurs world-wide [1]. This fungus produces large numbers of conidia that are released into the air [25]. Estimates indicate that humans can inhale a few hundred of these asexual spores of $A$. fumigatus a day $[2,6]$. Their small diameter of $2-3 \mu \mathrm{m}$ and hydrophobic surface enables them to reach the alveoli [7]. Yet, most of them

\footnotetext{
* Correspondence: id.valdesbarrera@uu.nl

'Microbiology, Department of Biology, Utrecht University, Utrecht, The Netherlands

Full list of author information is available at the end of the article
}

are trapped and removed by the mucociliary escalator or by immune cells present in the lung tissue. Upon germination, they can cause invasive or non-invasive forms of aspergillosis. The former is characterised by the penetration and infection of tissues [8]. A. fumigatus has been shown to secrete mycotoxins like gliotoxin, verruculogen, fumagillin and helvolic acid, which can affect ciliary beat frequency and promote colonization of lung epithelium $[9,10]$. Invasive aspergillosis most often occurs in individuals with impaired cell-mediated immunity [8]. Additionally this fungus is able to cause mycosis in animals such as cats and dogs [11]. For instance, it is responsible for most 
cases of sino-nasal aspergillosis in dogs (SNA) [12]. Canine SNA is clinicopathologically similar to chronic erosive non-invasive fungal sinusitis in humans [13]. It is characterized by the formation of fungal plaques (i.e. fungal biofilms) in the nasal cavity and frontal sinus. Other than in some invasive forms of aspergillosis in humans [14], no evidence of impaired innate or adaptive immune responses have been described for dogs suffering from SNA $[15,16]$. Notably, mesocephalic and dolichocephalic dogs seem to be affected with a higher frequency as compared to brachycephalic dogs for reasons that remain elusive but which could be related to a smaller sino-nasal surface area of the latter [13]. In cats A. fumigatus is one of the causative agents of upper respiratory aspergillosis (URTA). URTA in cats can be divided into sino-nasal aspergillosis (SNA) and sino-orbital aspergillosis (SOA) of which SOA is the most common condition. SNA in cats resembles SNA in dogs and is caused primarily by A. fumigatus but also by Aspergillus niger. SOA, on the other hand, is most commonly caused by Aspergillus felis sensu lato [17]. Still, these infections in humans, dogs and cats are, like most fungal infection in mammals, relatively uncommon, especially considering the ubiquity of $A$. fumigatus conidia in the environment.

Fungal infections are treated with a range of antimycotic compounds. The antifungal activity of azoles is based on the binding to ergosterol synthase. Both cyp51A and cyp $51 B$ of $A$. fumigatus encode for this lanosterol $14 \alpha$-demethylase. Azole resistance induced mutations have been described mainly in cyp51A [18-20]. These mutations can involve tandem repeats in the promotor area in combination with point mutations in the cyp51A gene. Of these, the $\mathrm{TR}_{34} / \mathrm{L} 98 \mathrm{H}[21,22]$ and $\mathrm{TR}_{46} / \mathrm{Y} 121 \mathrm{~F} / \mathrm{T} 289 \mathrm{~A}$ $[23,24]$ are most frequently reported with an incidence of up to $20 \% \%$ in the Netherlands depending on the site of isolation of the resistant strain [25]. Additionally it has been suggested that about $10 \%$ of azole resistant strains that does not possess a mutation of the cyp $51 \mathrm{~A}$ gene can be explained by increased activity in $\mathrm{ABC}$ transporters that helps to detoxificate the fungal cell from azoles, or mutation in other genes like hapE [20, 26, 27].

Here we performed a comparative phenotypic and genetic analysis of $A$. fumigatus isolates from dogs with SNA, human patients suspected of having invasive A. fumigatus infection from a well-defined group of high-risk patients from the haematology ward and the intensive care unit (ICU), and isolates from indoor and outdoor substrates. Phylogenetic inference based on calmodulin $(\mathrm{CaM})$ and beta-tubulin (ben $A$ ) sequences did not reveal $A$. fumigatus sub-groups but dog isolates were more variable in growth speed and morphology. Possibly, A. fumigatus evolves within the dog during the infection process by mutations and / or epigenetic variations.

\section{Methods}

\section{Fungal isolates and culturing}

A total of 87 isolates of $A$. fumigatus were used (Table 1; Additional file 1: Table S1) that were derived from the environment $(n=27)$, infected dogs $(n=27)$, and humans $(n=29)$. A fumigatus var. ellipticus type-strain [28], A. fumigatus Af293, and A. fumigatus Af1163 were included as reference strains. A. fumigatus isolates were originated from 9 dogs (Canine patient CP1-8.2, Additional file 1: Table S1) suffering from SNA presented at the Faculty of Veterinary Medicine in Utrecht between 2010 and 2012. One dog (CP8) was presented twice at the hospital due to a reinfection after 2 years (CP8.2 with isolates DTO 303-F1 and -F2, Additional file 1: Table S1). Hospitalized canine patients suspected to suffer from SNA were subjected to computer tomography $(\mathrm{CT})$, and endoscopic/rhinoscopic, and haematological analysis. Clinical signs specific of SNA are unilateral or bilateral mucopurulent nasal discharge, depigmentation of the nasal planum, an increased airflow through the nostrils, and an enlarged ipsilateral mandibular lymph node. In the case a fungal plaque was detected (Additional file 1: Table S1), tissue and blood samples were sent to the Veterinary Pathology Diagnostic Center and the Veterinary Diagnostic Laboratory of Utrecht University. Haematocrit, leucocytes,

Table 1 Overview of A. fumigatus isolates

\begin{tabular}{|c|c|c|c|c|}
\hline & Number of isolates & Provided by & Country of origin & Reference/Year \\
\hline \multirow[t]{2}{*}{ Environmental } & 23 & Westerdijk Institute Utrecht & The Netherlands and Germany & $2005-2008$ \\
\hline & 4 & Westerdijk Institute Utrecht & Ireland & [4], 2005 \\
\hline Canine isolates & 27 & $\begin{array}{l}\text { Clinical Sciences of Companion Animals, } \\
\text { Veterinary Medicine, Utrecht University }\end{array}$ & The Netherlands & 2010-2012 \\
\hline Human isolates & 29 & University Medical Centre Utrecht & The Netherlands & {$[30], 2011-2013$} \\
\hline $\begin{array}{l}\text { Aspergillius fumigatus Af293 } \\
\text { (CBS 126847) }\end{array}$ & 1 & Westerdijk Institute Utrecht & UK & [51], 1993 \\
\hline Aspergillius fumigatus A1163 & 1 & Westerdijk institute Utrecht & France & {$[52], 2008$} \\
\hline Aspergillius fumigatus var. ellipticus & 1 & Westerdijk Institute Utrecht & USA & [28], 1965 \\
\hline
\end{tabular}


blood cell differentiation, total protein, albumin and the protein spectrum was measured in the blood samples.

Fungal plaques were obtained via trephination of the frontal sinus and/or rhinoscopic removal in the nasal sinus with a 30 degrees $2.7 \mathrm{~mm}$ rigid endoscope and using a combination of suction and a metal hook. Trephination was performed if mycotic plaques in the frontal sinus were diagnosed by CT. After removal of the fungal plaques the nasal sinus was flushed in most cases with clotrimazol for $15 \mathrm{~min}$ each in ventral, left and right lateral, and dorsal recumbency, followed by flushing for $15 \mathrm{~min}$ in ventral recumbency, after which the clotrimazol was allowed to leave the nasal sinus by gravity (head down). Part of the fungal plaque was immediately frozen in liquid nitrogen and stored at $-80^{\circ}$ C. Remaining material was placed on ice and used for microbial culturing and histological analysis. Culturing was started at the same day on potato dextrose agar (PDA, Becton Dickinson, Le-Pont-De-Claix, France) and care was taken to inoculate plates with different pieces of fungal plaques of the same dog. Colonies incubated for 2 days at $37^{\circ} \mathrm{C}$ presenting macroscopical characteristics of A. fumigatus were sub-cultured on PDA plates using vegetative mycelium from the outer part of the colony as an inoculum. Conidial suspensions were made as described [29].

Isolates from $A$. fumigatus were obtained from 9 high-risk patients from the intensive care and haematology units of the Utrecht University Medical Center (UMCU) who were suspected to have developed invasive aspergillosis (patients HP1-9; Additional file 1: Table S1) but none of them had received prophylactic antifungal therapy. These isolates were obtained between 2011 and 2013 from sputum, bronchoalveolar lavage, or pleural fluid (Additional file 1: Table S1; [30]). The human isolates were provided as colonies on Malt Extract agar (MEA) plates. In order to eliminate the possibility of having more than one isolate per plate, colonies were sub-cultured on PDA plates using vegetative mycelium from the edge and the centre of the colonies as inoculum. Plates were inoculated by tracing a double zigzag pattern with a plastic inoculating loop. After incubation at $37{ }^{\circ} \mathrm{C}$ for 3 days, plates were inspected for the presence of colonies with different morphology. Clearly distinct colonies were treated as different isolates. Conidial suspensions were prepared as described [29].

\section{Phenotypic characterization of fungal isolates}

Phenotypic characterization was performed on creatine sucrose agar (CREA), Czapek yeast agar (CYA), CYA with $5 \% \mathrm{NaCl}$ (CYAS), dichloran 18\% glycerol agar (DG18), malt extract agar (MEA), yeast extract sucrose agar (YES) as recommended [29]. A 3-point inoculation was used and plates were incubated lid-side up at $25{ }^{\circ} \mathrm{C}$ for a period of 7 days in the dark. Diameter of colonies was analysed by ImageJ [31] after taken photographs from a fixed height with a Canon camera with a telephoto lens. They were subjected to PCA and k-means clustering with $\mathrm{k}=3$ corresponding to the initial number of groups (i.e. indoor and outdoor substrates, dog, and human). In addition, colour of the medium underneath the colony, spatial distribution of conidia formation, and morphology of the conidiophores was analysed. Pictures of conidiophores and conidia were made as described [29]. Mycelium was scraped of colonies that had been grown on MEA for 7 days. This mycelium was mounted on an object glass in a drop of lactic acid and a very small drop of ethanol (70\%) was used to flush the excess conidia outward. Samples were studied using Olympus BH2 and Zeiss Axioskop microscopes.

\section{DNA isolation, sequencing, genetic and phylogenetic analysis}

Genomic DNA was isolated with the UltraClean Microbial DNA Isolation kit (MO BIO Laboratories, Solana Beach CA) and used to PCR amplify fragments of calmodulin $(C a M), \beta$-tubulin (benA), and the mating type loci MAT1-1 and MAT1-2 (Table 2; [29]). Sequencing of the reverse and forward strands was performed using the Big Dye $^{\circ}$ Terminator Cycle Sequencing Ready Reaction kit (Applied Biosystems, Foster City, CA, USA). Products of the sequencing reactions were purified using Sephadex G-50 gel filtration (GE Healthcare, Little Chalfont, Buckinghamshire, UK), equilibrated in double-distilled water,

Table 2 Primers and temperature conditions used for PCR [29]

\begin{tabular}{|c|c|c|c|c|c|c|}
\hline Locus & Primer & Annealing temp $\left({ }^{\circ} \mathrm{C}\right)$ & Cycles & Direction & Sequence $\left(5^{\prime}-3^{\prime}\right)$ & Reference \\
\hline \multirow[t]{2}{*}{ CaM } & CMD5 & 55 & 35 & Forward & CCGAGTACAAGGARGCCTTC & [53] \\
\hline & CMD6 & 55 & 35 & Reverse & CCGATRGAGGTCATRACG TGG & \\
\hline \multirow[t]{2}{*}{ BenA } & $\mathrm{Bt}_{2} \mathrm{a}$ & 55 & 35 & Forward & GGTAACCAAATCGGTGCTGTTC & [54] \\
\hline & $\mathrm{Bt}_{2} \mathrm{~b}$ & 55 & 35 & Reverse & ACCCTCAGTGTAGTGACCCTTGGC & \\
\hline MAT1-1 & $\begin{array}{l}\text { AFM1_F65655 } \\
\text { MAT1_R6215 }\end{array}$ & $\begin{array}{l}48 \\
48\end{array}$ & $\begin{array}{l}30 \\
30\end{array}$ & $\begin{array}{l}\text { Forward } \\
\text { Reverse }\end{array}$ & $\begin{array}{l}\text { CCTYGACGMGATGGGITGG } \\
\text { TGTCAAAGARTCCAAAAGGAGG }\end{array}$ & this study \\
\hline MAT1-2 & $\begin{array}{l}\text { MAT2_F6086 } \\
\text { MAT2_R6580 }\end{array}$ & $\begin{array}{l}48 \\
48\end{array}$ & $\begin{array}{l}30 \\
30\end{array}$ & $\begin{array}{l}\text { Forward } \\
\text { Reverse }\end{array}$ & $\begin{array}{l}\text { TCGACAAGATCAAAWCYCGTC } \\
\text { CTTYTTGARCTCTTCYGCTAGG }\end{array}$ & this study \\
\hline
\end{tabular}


and analyzed using the ABI PRISM 310 Genetic Analyzer (Applied Biosystems). The CaM and benA sequences of the isolates and $A$. niger NRRL326, $A$. clavatus NRRL1, $A$. felis CBS130245, A. lentulus NRRL35552, A. fumigatus NRRL5109, A. fumigatus NRRL164, A. fumigatus NRRL163, and $N$. fischeri NRRL181 were used to construct a phylogenetic inference. Phylogenetic trees were constructed using the ETE Toolkit pipeline [32] and visualized with Figtree v1.4.2 (http://tree.bio.ed.ac.uk/software/figtree/).

\section{Microsatellite analysis}

Microsatellite genotyping was performed using the STR $A f$ assay as described [33]. All nine markers data were imported into R package poppr [34] to construct a minimum spanning tree. Bruvo distance was used to determine genetic diversity between isolates [35].

\section{TR profiling and microdilution assay}

$\mathrm{TR}_{34}$ and $\mathrm{TR}_{46}$ repeat analysis within cyp51A was performed using qPCR as described [36], additional information about the sequence of the cyp51A was available for human isolates (Additional file 1: Table S1). Microdilution assays to determine Minimum inhibitory concentrations (MIC) of itraconazole (Santa Cruz Biotech, Dallas, USA), posaconazole (MSD, Kenilworth, USA) and voriconazole (Pfizer, New York, USA) were performed according to EUCAST (http://www.eucast.org/fileadmin/src/media/PDFs/ EUCAST_files/AFST/Files/EUCAST_E_Def_9_3_Mould_ testing_definitive.pdf).

\section{Results}

Histology and haematological analysis

CT scan and rhinoscopy confirmed sinonasal mycosis in 9 dogs presented at the Veterinary hospital at Utrecht University. Histopathological biopsies showed non-invading hyphae on the mucosal surface. The lamina propria was not invaded (Additional file 2: Figure S1). Conidiophores were rarily observed, which is consistent with the observation that fungal plaques in the nasal cavities were white (Additional file 2: Figure S1B). The lamina propria was infiltrated by large amounts of lymphocytes, plasma cells, and neutrophil granulocytes.

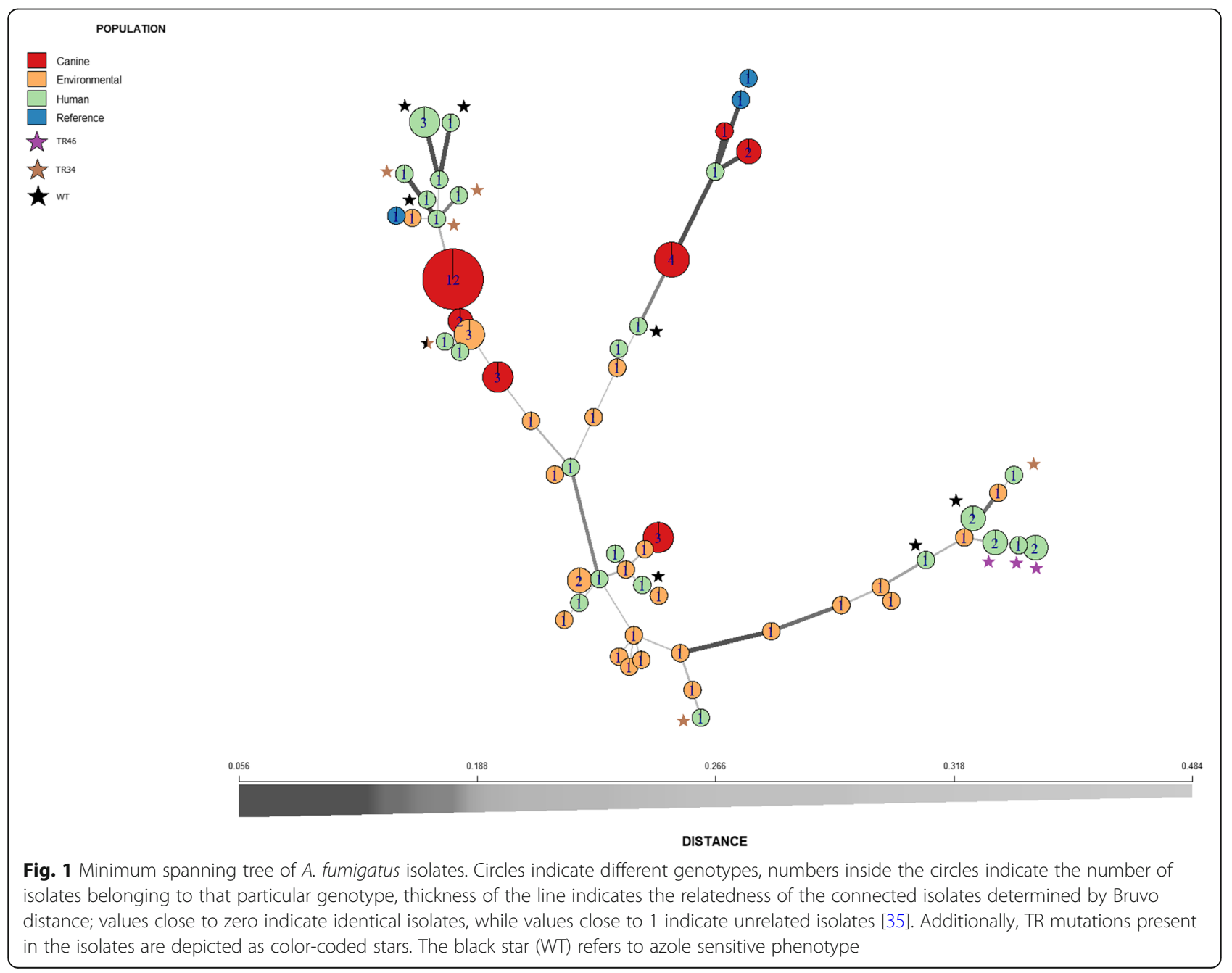


Haematological analysis showed differences in the levels of blood albumin in all dogs. Four dogs showed signs of mild blood loss in the weeks before the treatment, which could explain the hypoalbuminemia. Together, all 9 dogs suffered from a chronic lymphoplasmacellular rhinitis with fungal hyphae and ulcerations.

\section{Genotyping and phylogeny}

A phylogenetic tree of the A. fumigatus isolates was constructed using the benA and CaM genes (Additional file 3: Figure S2). In 4 out of 87 isolates only one of these genes was amplified successfully (Additional file 1: Table S1). The tree based on CaM (Additional file 3: Figure S2) showed no subgroups of isolates. They all grouped with $A$. fumigatus Af293 and NRRL 163 (Additional file 3: Figure S2, left) but not with the emerging fungal pathogen $A$. felis [17] (Additional file 3: Figure S2). The same result was obtained when the tree was constructed with $\operatorname{ben} A$ sequences (Additional file 3: Figure S2, right), indicating that these markers are unable to distinguish between the set of isolates used in this study.

Fungal isolates from an individual dog were of the same mating type, while both mating types were present in individual human patients (4 out of 9). The 9 infected dogs had either isolates with MAT1.1 (4) or MAT1.2 (5). The fungal isolates from humans (15 isolates having MAT1.1 and 12 isolates having MAT1.2) and indoor and outdoor substrates (12 isolates having MAT1.1 and 13 isolates having MAT1.2) also showed a ratio close to 1 . Because of the inability of the previous markers to differentiate between isolates, genetic heterogeneity was further analyzed by microsatellite analysis using the STRAf assay. A total of 59 A. fumigatus genotypes were found within the 87 isolates with a genetic distance between the isolates ranging between 0.056 and 0.496 (Fig. 1). Most of the isolates were found to be of a unique distant genotype. In the case of indoor and outdoor substrates only two genotypes were represented by more than one isolate. Similarly, most of the isolates from a human individual were of a different genotype (Fig. 2). Moreover, genotypes were different between human individuals except for genotype 10 (Additional file 1: Table S1) which was found in two human patients. In contrast, the 27 dog isolates from the 9 dogs grouped only in six clusters. The isolates derived from an individual dog all had the same genotype (Fig. 2, Additional file 1: Table S1).

\section{Phenotyping of $A$. fumigatus isolates}

Most isolates showed a colony and conidiophore morphology typical for A. fumigatus(Fig. 3). However, the isolates from dogs were phenotypically more diverse as compared to those from the environment or humans (Tables 3 and 4). Variation was also observed between isolates from a single dog. This was the case for dogs CP1, CP2, CP4, CP7 and CP8.2. Conidiophore morphology was atypical in 12 out of 27 isolates from dogs.

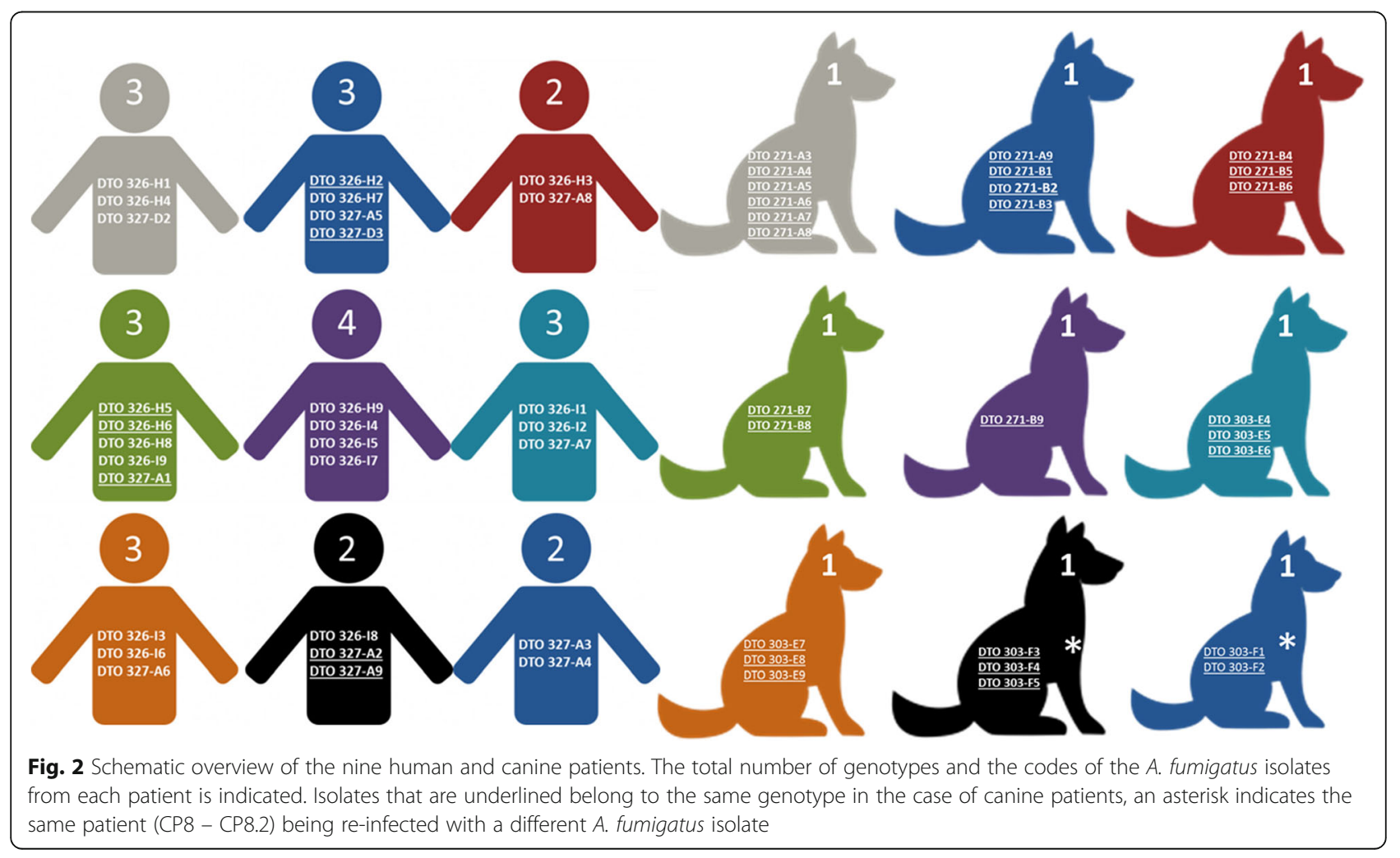




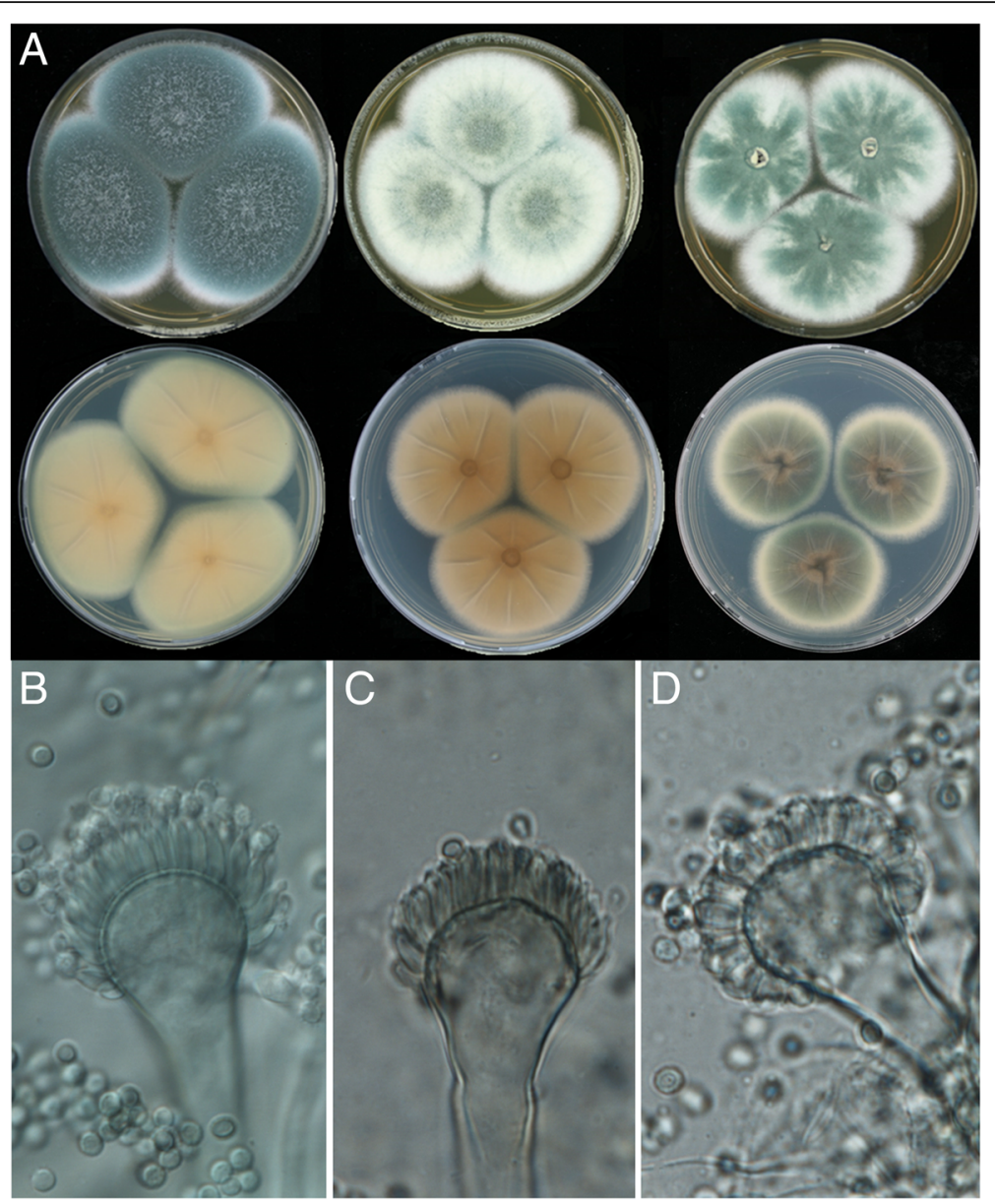

Fig. 3 Morphology of colonies (a) and conidiophores and conidia (B-D) of A. fumigatus isolates from dogs, humans and the environment. Top row of panel A shows the obverse side of the colony grown on MEA of isolates DTO 028-D6, DTO 271-A5, and DTO 303-E8, while the bottom row shows the reverse side of CYA-grown colonies of DTO 028-D6, DTO 326-19, DTO 326-H2. A conidiophore of DTO 327-D3 with flask-shaped phialides and abundant production of conidia is shown in (b), while (c) shows similar phialides of isolate DTO 326-19 with sparse production of conidia. Reduced, cylindrical shaped phialides of DTO 303-F2 and abundant production of conidia are shown in (d)

Table 3 Number of isolates from human, dog and indoor and outdoor substrates per phenotypic trait

\begin{tabular}{|c|c|c|c|c|c|}
\hline & Phenotype & Canine (27) & Environmental (27) & Human (29) & Reference (3) \\
\hline \multirow{4}{*}{$\begin{array}{l}\text { Degree of sporulation and } \\
\text { phialide shape in MEA }\end{array}$} & Strong sporulation and cylindrical phialides & 1 & & & \\
\hline & Strong sporulation and flask-shaped phialides & 15 & 27 & 29 & 3 \\
\hline & Sparse sporulation and flask-shaped phialides & 11 & & & \\
\hline & Dark greenish colony & 14 & 27 & 29 & 2 \\
\hline \multirow[t]{3}{*}{ Sporulation in MEA } & $\begin{array}{l}\text { Mostly whitish colony, with the center of the } \\
\text { colony green followed by concentric rings of } \\
\text { pale yellowish green }\end{array}$ & 12 & & & 1 \\
\hline & Whitish colony with star-like green patches & 1 & & & \\
\hline & Acid production absent & 20 & 15 & 29 & 3 \\
\hline \multirow[t]{2}{*}{ Acid production on CREA } & Acid production present & 7 & 12 & & \\
\hline & Brownish & 1 & & 3 & \\
\hline \multirow[t]{2}{*}{ Reverse color on CYA } & Green with brown center and white margins & & 1 & 2 & 1 \\
\hline & White & 26 & 26 & 24 & 2 \\
\hline
\end{tabular}


Table 4 Distribution of phenotypes of A. fumigatus isolated from 9 dogs suffering from SNA

\begin{tabular}{|c|c|c|c|c|c|c|c|c|c|c|}
\hline & Phenotype & CP1 (6) & CP2(4) & $\mathrm{CP} 3(3)$ & CP4 (2) & CP5(1) & CP6(3) & $\mathrm{CP} 7(3)$ & CP8(3) & CP8.2(2) \\
\hline \multirow{3}{*}{$\begin{array}{l}\text { Degree of sporulation and } \\
\text { phialide shape in MEA }\end{array}$} & Strong sporulation and cylindrical phialides & & & & & & & & & 1 \\
\hline & Strong sporulation and flask-shaped phialides & 1 & 1 & 3 & 2 & 1 & 3 & 3 & & 1 \\
\hline & Sparse sporulation and flask-shaped phialides & 5 & 3 & & & & & & 3 & \\
\hline \multirow[t]{3}{*}{ Sporulation in MEA } & Dark greenish colony & 1 & 1 & 3 & 1 & 1 & 3 & 2 & & 2 \\
\hline & $\begin{array}{l}\text { Mostly whitish colony, with the centre of the } \\
\text { colony green followed by concentric rings of } \\
\text { pale yellowish green }\end{array}$ & 5 & 3 & & 1 & & & & 3 & \\
\hline & Whitish colony with star-like green patches & & & & & & & 1 & & \\
\hline \multirow[t]{2}{*}{ Pigmentation in CREA } & No pigment & 5 & 4 & & 2 & 1 & & 3 & 3 & 2 \\
\hline & Yellow pigment & 1 & & 3 & & & 3 & & & \\
\hline \multirow[t]{2}{*}{ Pigmentation in CYA } & Brownish reverse & & 1 & & & & & & & \\
\hline & White reverse & 6 & 3 & 3 & 2 & 1 & 3 & 3 & 3 & 2 \\
\hline
\end{tabular}

The total number of isolates per dog is between brackets

Furthermore, whitish colonies with concentric green rings of conidia forming conidiophores were observed in 12 out of the 27 fungal isolates (Fig. 3). This phenotype was associated with reduced production of conidia as compared to the fungal isolates from human patients and outdoor en indoor substrates. Acidification of CREA medium was not observed in the case of human isolates and the reference strains but was detected in 7 out of 27 fungal isolates from dogs and 12 out of 27 environmental isolates (Table 3 and Additional file 1: Table S1). Additionally, high variation was observed in the average diameter of colonies of isolates from dogs grown on CREA, MEA, YES, DG18, CYAS (Table 5). PCA and $\mathrm{k}$-means clustering using colony diameter as a proxy for growth showed that one cluster contained only 5 isolates from dogs (DTO 303-E6, DTO 303-F5, DTO 303-E5, DTO 271-B3, DTO 271-B2) as well as A. fumigatus var. ellipticus (cluster 1 in Fig. 4) The isolates from indoor and outdoor substrates and human patients were distributed in clusters 2 and 3 . Fourteen and eight isolates from dogs clustered in clusters 2 and 3, respectively (Fig. 4).

\section{TR profiling and resistance to azoles}

Microdilution assays showed that 12 out of the $29 \mathrm{hu}-$ man isolates were resistant to itraconazole, posaconazole and/or voriconazole. Of these isolates, 6 showed a $\mathrm{TR}_{34}$ promotor duplication in cyp51A and 5 a $\mathrm{TR}_{46}$ duplication in this gene. One resistant (DTO 060-G9) and 3 intermediate resistant (DTO 028-D6, DTO 086-C1, DTO 089-G1) posaconazole strains were identified in the environmental isolates from the Netherlands. Dog isolates were all sensitive to the azoles tested, and both groups of strains (Dog and environmental) did not show $\mathrm{TR}_{34}$ and $\mathrm{TR}_{46}$ mutations. The Af293 strain was sensitive to itraconazole and posaconazole and resistant to voriconazole like the results presented by Mowat et al. [37] (Additional file 1: Table S1) and the EUCAST MIC distribution for Af293 (Additional file 4: Figure S3) Af293 is however generally considered susceptible for this azole.

\section{Discussion}

We assessed phenotypic and genetic differences between strains of $A$. fumigatus isolated from indoor and outdoor substrates and from infected humans and dogs. Genetic analyses did not indicate the existence of sub-groups within A. fumigatus specialized in infecting human or dog. A notable variation in phialide morphology, sporulation, colony size, and colony color was observed between strains isolated from dogs suffering from SNA; even between isolates from the same infected individual. This phenotypic variability was not associated with genetic differences in the benA, CaM, MAT1-1, MAT1-2,

Table 5 Mean diameter with standard deviation of colonies $(\mathrm{mm})$ on each medium for each investigated isolate set

\begin{tabular}{lllll}
\hline Medium & Dog isolates & Environmental isolates & Human isolates & References \\
\hline CREA & $31.81 \pm 10.52$ & $26.73 \pm 6.90$ & $29.55 \pm 7.98$ & $25.31 \pm 12.02$ \\
CYA & $36.90 \pm 11.25$ & $44.57 \pm 4.62$ & $42.44 \pm 4.32$ & $39.98 \pm 10.96$ \\
CYAS & $28.66 \pm 10.76$ & $25.54 \pm 3.53$ & $24.83 \pm 6.81$ & $14.74 \pm 11.30$ \\
DG18 & $28.65 \pm 9.99$ & $19.92 \pm 2.85$ & $28.67 \pm 8.76$ & $11.56 \pm 11.86$ \\
MEA & $36.37 \pm 11.04$ & $44.55 \pm 5.96$ & $45.63 \pm 3.87$ & $39.06 \pm 11.22$ \\
YES & $38.98 \pm 11.90$ & $49.02 \pm 3.20$ & $47.36 \pm 5.72$ & $41.78 \pm 13.26$ \\
\hline
\end{tabular}




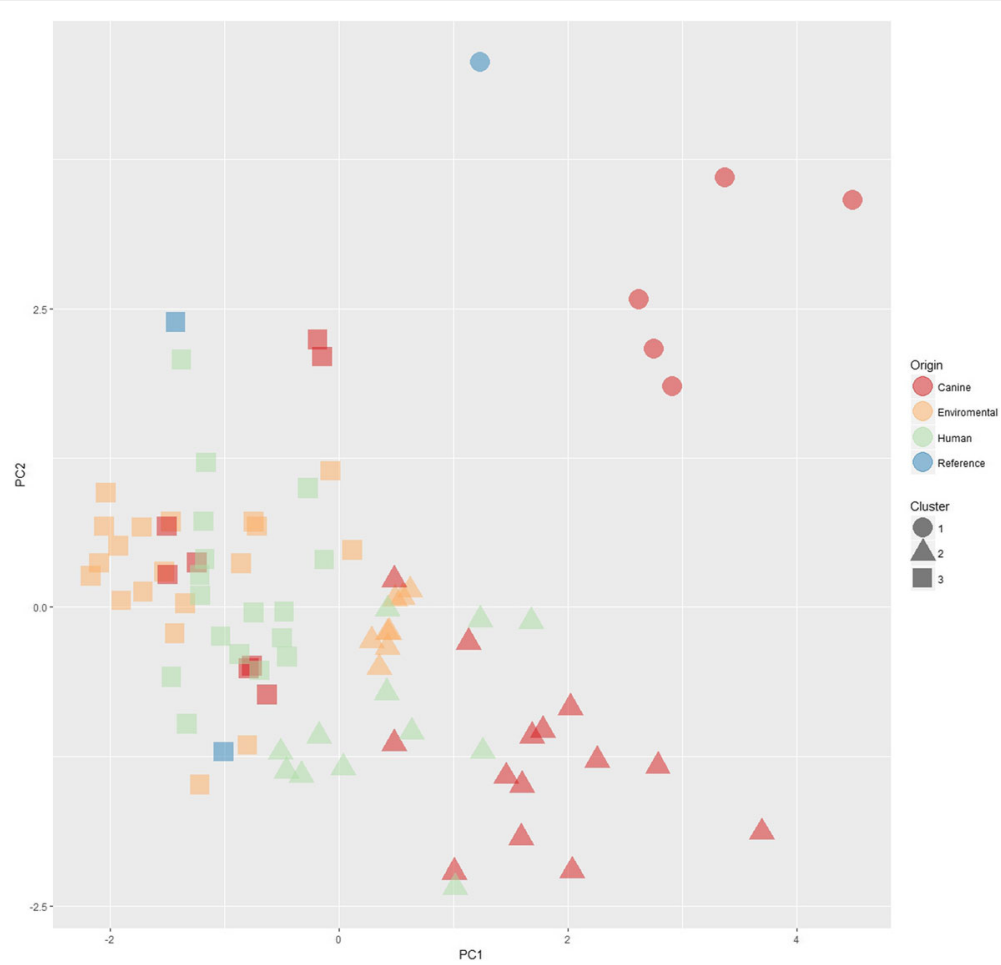

Fig. 4 PCA and K-means clustering of A. fumigatus isolates based on colony grown on several media. The arrow indicates the position of $A$. fumigatus var. ellipticus

cyp51A loci and microsatellites. This indicates that the dogs were infected with a single strain. It is tempting to speculate that the phenotypic differences evolve within the dog during the infection process due to epigenetic changes or mutations. The fact that phenotypic variability was hardly observed in isolates from human and from indoor and outdoor substrates suggests that the dog sinus induces phenotypic evolution. SNA in dogs is a chronic infection starting with an inoculum in the front of the sinus [13]. This may be the cause of the observed variation in the dog isolates. A long exposure to a stressful environment and for example host immune response, nutrient, and gas (oxygen) availability may act as a selection pressure [36]. Reduced asexual reproduction, as observed in 11 out of 27 dog isolates can be an adaptation to increase fitness in the host [38, 39]. Similarly, higher growth rate at $37{ }^{\circ} \mathrm{C}$ have been correlated with increased virulence [40]. Notably, in our study isolates from dog and humans had a higher growth rate on DG18 media as compared to the environmental isolates. The real meaning of this variation of growth for virulence is unclear and requires further investigation.

The observation that a single genotype persist in a dog could suggest that the spread of the fungus in the sinus proceeds gradually associated with a non-sporulating biofilm but not invading the epithelium of the sinus [41]. The infection within human patients is also different from dogs because human patients can carry multiple A. fumigatus strains [42-44]. This was confirmed in our study by the presence of $M A T 1-1$ and MAT1-2 strains isolated from an individual patient that had different microsatellite profiles. It should be noted that it is difficult to associate the human isolates with a proven infection since they were obtained via bronchoalveolar lavage or sputum samples and not from deep tissue samples.

Clinical azole resistance in the Netherlands is $5-20 \%$ for A. fumigatus isolated from human patients [25, 30, 45]. The majority $(89 \%)$ contain $\mathrm{TR}_{34} / \mathrm{L} 98 \mathrm{H}$ or $\mathrm{TR}_{46} /$ Y121F/T289A mutations, while $11 \%$ of the resistant isolates carry wild type cyp51A [46]. In our study, tandem repeats $\mathrm{TR}_{34}$ or $\mathrm{TR}_{46}$ were only detected in human clinical isolates. A single posaconazole resistant isolate from environmental isolates was found which was not TR associated and future genome sequencing should illuminate the resistance mechanism involved. Jensen and colleagues [47] found few azole resistant environmental isolates (4/133) in the National Mycology Reference Laboratory of Denmark. In contrast, Klaassen et al. [48] reported that 16 out of the 213 clinical isolates and 9 of the 42 environmental isolates contained the $\mathrm{TR}_{34} / \mathrm{L} 98 \mathrm{H}$ allele associated with multi-triazole-resistance. Clearly, extensive azole fungicide use in the environment can result in selection of azole resistant strains and complicate 
clinical management [49]. A survey including whole genome sequencing (WGS) between environmental and clinical isolates can give clues about the evolution of resistance in both niches [50].

\section{Conclusion}

Taken together our results showed that phenotypic and genetic heterogenicity is a key factor to understand several aspects of infections caused by A.fumigatus. Dog SNA isolates were phenotypically more diverse than human and environmental isolates. Additionally, using the STRAf assay we observed that fungal plaques from dog suffering SNA harbour isolates genetically identical (one genotype), while humans with suspected IPA are infected with multiple genotypes. Phenotypic variation in dog isolates might be due to genomic differences or epigenetic variations and due to host adaption during the chronic infection process in dogs. New experiments aiming to understand the genomic, epigenetic and physiological adaptations of the isolates studied can provide clues host-driven evolution and its implication in virulence and control of the disease caused by this pathogen in humans.

\section{Additional file}

Additional file 1: Table S1. Excel file with detailed phenotypic and genetic data .n.d, not determined (no PCR product or sequence obtained) (XLSX $20 \mathrm{~kb}$ )

Additional file 2: Figure S1. Histology section of the mucosa of a dog with SNA (A) and rhinoscopic image of the fungal plaque within the sinus nasalis (B). Arrow in (A) indicates mucosa tissue with high infiltration of immune cells. Note that the hyphae indicated with a star in (B) do not penetrate the epithelial tissue (TIF $2505 \mathrm{~kb}$ )

Additional file 3: Figure S2. Phylogenetic inference constructed using CaM (left) and benA (right) sequences of human, dog, and indoor and outdoor isolates as well as reference strains. Green represents indoor and outdoor isolates, blue and red represent isolates from dogs and human, respectively, and black represents reference strains. A.felis indicated with *. (TIF $2808 \mathrm{~kb}$ )

Additional file 4: Figure S3. Voriconazole MIC distribution for Microdilution assay from EUCAST (consulted 22/06/2018), note that MIC of $4 \mathrm{mg} / \mathrm{L}$ are reported. (JPG $108 \mathrm{~kb}$ )

\section{Abbreviations}

CREA: Creatine sucrose agar; CT: Computed tomography scan; CYA: Czapek yeast agar; CYAS: Czapek yeast agar + 5\% NaCl; DG18: Dichloran 18\% glycerol agar; EUCAST: European Committee on Antimicrobial Susceptibility Testing; IPA: Invasive pulmonary aspergillosis; MEA: Malt extract agar; MIC: Minimum inhibitory concentration; PCA: Principal components analysis; PDA: Potato dextrose agar; SNA: Sino nasal aspergilosis; SOA: Sino orbital aspergillosis; STRAf: Short tandem repeats assay for Aspergillus fumigatus

\section{Availability of data and materials}

The datasets used and/or analyzed during the current study are available from the corresponding author on reasonable request.

\section{Authors' contributions}

HABW and $\mathrm{HC}$ conceived and designed the experiments. IV, JB, AH, NE, FH, JFM, PJH and JH performed the experiments. IV, JB and $\mathrm{HC}$ analyzed the data and prepared figures. IV, JB and HC prepared reagents/materials/analysis tools. IV, AH, FH, PJH, HABW, HC and JH contributed to writing and revision of the manuscript. All authors read and approved the final manuscript.

Ethics approval and consent to participate

Isolates from dogs were obtained with owner's consent applying a standardized protocol. Standard care was performed when obtaining the human isolates applying a standardized protocol.

Consent for publication

Not applicable

\section{Competing interests}

The authors declare that they have no competing interests.

\section{Publisher's Note}

Springer Nature remains neutral with regard to jurisdictional claims in published maps and institutional affiliations.

\section{Author details}

${ }^{1}$ Microbiology, Department of Biology, Utrecht University, Utrecht, The Netherlands. ${ }^{2}$ Veterinary Medicine, Utrecht University, Utrecht, The Netherlands. ${ }^{3}$ Department of Medical Microbiology and Infectious Diseases, Canisius-Wilhelmina Hospital, Nijmegen, The Netherlands. ${ }^{4}$ Centre of Expertise in Mycology Radboudumc/CWZ, Nijmegen, The Netherlands. ${ }^{5}$ Westerdijk Institute, Utrecht, The Netherlands. ${ }^{6}$ University Medical Center Utrecht, Utrecht, The Netherlands.

Received: 12 April 2018 Accepted: 21 August 2018

Published online: 17 September 2018

\section{References}

1. Kwon-Chung KJ, Sugui JA. Aspergillus fumigatus-what makes the species a ubiquitous human fungal pathogen? PLoS Pathog. 2013;9(12):e1003743.

2. Mullins J, Hutcheson PS, Slavin RG. Aspergillus fumigatus spore concentration in outside air: Cardiff and St Louis compared. Clin Allergy. 1984;14(4):351.

3. Mullins J, Harvey R, Seaton A. Sources and incidence of airborne Aspergillus fumigatus (Fres). Clin Allergy. 1976;6(3):209-17.

4. O'Gorman CM, Fuller HT. Prevalence of culturable airborne spores of selected allergenic and pathogenic fungi in outdoor air. Atmos Environ. 2008:42(18):4355-68.

5. VandenBergh MFQ, Verweij PE, Voss A. Epidemiology of nosocomial fungal infections: invasive aspergillosis and the environment. Diagn Microbiol Infect Dis. 1999;34(3):221-7.

6. Latgé JP. Aspergillus fumigatus and Aspergillosis. Clin Microbiol Rev. 1999; 12(2):310-50.

7. Ben-Ami R, Lewis RE, Kontoyiannis DP. Enemy of the (immunosuppressed) state: an update on the pathogenesis of Aspergillus fumigatus infection. Br J Haematol. 2010;150(4):406-17.

8. Park SJ, Mehrad B. Innate immunity to Aspergillus species. Clin Microbiol Rev. 2009;22(4):535-51.

9. Khoufache K, Puel O, Loiseau N, Delaforge M, Rivollet D, Coste A, Cordonnier C, Escudier E, Botterel F, Bretagne S. Verruculogen associated with Aspergillus fumigatus hyphae and conidia modifies the electrophysiological properties of human nasal epithelial cells. BMC Microbiol. 2007;7(1):5.

10. Amitani R, Taylor G, Elezis EN, Llewellyn-Jones C, Mitchell J, Kuze F, Cole PJ, Wilson R. Purification and characterization of factors produced by Aspergillus fumigatus which affect human ciliated respiratory epithelium. Infect Immun. 1995;63(9):3266-71.

11. Pitt J. The current role of Aspergillus and Penicillium in human and animal health. Med Mycol. 1994;32(S1):17-32.

12. Peeters D, Clercx C. Update on canine sinonasal aspergillosis. Vet Clin N Am Small Anim Pract. 2007;37(5):901-16.

13. Sharman MJ, Mansfield CS. Sinonasal aspergillosis in dogs: a review. J Small Anim Pract. 2012;53(8):434-44.

14. Chakrabarti A, Das A, Panda N. Overview of fungal rhinosinusitis. Indian J Otolaryngol Head Neck Surg. 2004;56(4):251-8.

15. Peeters D, Peters IR, Clercx C, Day MJ. Quantification of mRNA encoding cytokines and chemokines in nasal biopsies from dogs with sino-nasal aspergillosis. Vet Microbiol. 2006;114(3):318-26. 
16. Day MJ. Canine sino-nasal aspergillosis: parallels with human disease. Med Mycol. 2009;47(S1):S323.

17. Barrs VR, van Doorn TM, Houbraken J, Kidd SE, Martin P, Pinheiro MD, Richardson M, Varga J, Samson RA. Aspergillus felis sp nov., an emerging agent of invasive aspergillosis in humans, cats, and dogs. PLoS One. 2013; 8(6):e64871.

18. Mellado E, Garcia-Effron G, Alcazar-Fuoli L, Cuenca-Estrella M, RodriguezTudela JL. Substitutions at methionine 220 in the $14 a$-sterol demethylase (Cyp51A) of Aspergillus fumigatus are responsible for resistance in vitro to azole antifungal drugs. Antimicrob Agents Chemother. 2004;48(7):2747.

19. Diaz-Guerra TM, Mellado E, Cuenca-Estrella M, Rodriguez-Tudela JL. A point mutation in the $14 a-$ sterol demethylase gene cyp51A contributes to itraconazole resistance in Aspergillus fumigatus. Antimicrob Agents Chemother. 2003;47(3):1120-4.

20. Meis JF, Chowdhary A, Rhodes JL, Fisher MC, Verweij PE. Clinical implications of globally emerging azole resistance in Aspergillus fumigatus. Philos Trans R Soc Lond Ser B Biol Sci. 2016;371(1709) https://doi.org/10. 1098/rstb.2015.0460

21. Snelders E, van der Lee HA, Kuijpers J, Rijs AJ, Varga J, Samson RA, Mellado E, Donders AR, Melchers WJ, Verweij PE. Emergence of azole resistance in Aspergillus fumigatus and spread of a single resistance mechanism. PLoS Med. 2008;5(11):e219.

22. Arenup MC, Mavridou E, Mortensen KL, Snelders E, Frimodt-Moller N, Khan $\mathrm{H}$, Melchers WJG, Verweij PE. Development of azole resistance in Aspergillus fumigatus during azole therapy associated with change in virulence. PLoS One. 2010;5(4):e10080.

23. Snelders E, Melchers WJG, Verweij PE. Azole resistance in Aspergillus fumigatus: a new challenge in the management of invasive aspergillosis? Future Microbiol. 2011;6(3):335.

24. van der Linden JWM, Camps SMT, Kampinga GA, Arends JP, DebetsOssenkopp YJ, Haas PJ, Rijnders BJ, Kuijper EJ, Tiel FH, Varga J, Karawajczyk A, Zoll J, Melchers WJG, Verweij PE. Aspergillosis due to voriconazole highly resistant Aspergillus fumigatus and recovery of genetically related resistant isolates from domiciles. Clin Infect Dis. 2013;57(4):513-20.

25. Lestrade PPA, Meis JF, Arends JP, van der Beek, Martha T, de Brauwer E, van Dijk K, de Greeff SC, Haas P, Hodiamont CJ, Kuijper EJ, Leenstra T, Muller AE, Lashof O, Astrid ML, Rijnders BJ, Roelofsen E, Rozemeijer W, Tersmette M, Terveer EM, Verduin CM, Wolfhagen MJHM, Melchers WJG, Verweij PE. Diagnosis and management of aspergillosis in the Netherlands: a national survey. Mycoses. 2016;59(2):101-7.

26. Chowdhary A, Sharma C, Meis JF. Azole-resistant Aspergillosis: epidemiology, molecular mechanisms, and treatment. J Infect Dis. 2017; 216(suppl_3):S444

27. Meneau I, Coste AT, Sanglard D. Identification of Aspergillus fumigatus multidrug transporter genes and their potential involvement in antifungal resistance. Med Mycol. 2016;54(6):616-27.

28. Raper KB, Fennell DI. The genus Aspergillus. New York: Krieger; 1965.

29. Samson RA, Visagie C, Houbraken J, Hong S, Hubka V, Klaassen CHW, Perrone G, Seifert KA, Susca A, Tanney JB, Varga J, Kocsube S, Szigeti G, Yaguchi T, Frisvad JC. Phylogeny, identification and nomenclature of the genus Aspergillus. Stud Mycol. 2014;78(78):141-73.

30. Fuhren J, Voskuil WS, Boel CHE, Haas PJA, Hagen F, Meis JF, Kusters JG. High prevalence of azole resistance in Aspergillus fumigatus isolates from high-risk patients. J Antimicrob Chemother. 2015;70(10):2894.

31. Schneider CA, Rasband WS, Eliceiri KW. NIH image to ImageJ: 25 years of image analysis. Nat Methods. 2012;9(7):671.

32. Huerta-Cepas J, Serra F, Bork P. ETE 3: reconstruction, analysis, and visualization of phylogenomic data. Mol Biol Evol. 2016;33(6):1635-8.

33. De Valk HA, Meis J, Curfs IM, Muehlethaler K, Mouton JW, Klaassen C. Use of a novel panel of nine short tandem repeats for exact and high-resolution fingerprinting of Aspergillus fumigatus isolates. J Clin Microbiol. 2005;43(8): 4112-20.

34. Kamvar ZN, Tabima JF, Grunwald NJ. Poppr: an R package for genetic analysis of populations with clonal, partially clonal, and/or sexual reproduction. PeerJ. 2014;2:e281.

35. Bruvo R, Michiels NK, D'Souza TG, Schulenburg H. A simple method for the calculation of microsatellite genotype distances irrespective of ploidy level. Mol Ecol. 2004;13(7):2101-6.

36. Mellado E, Garcia-Effron G, Alcázar-Fuoli L, Melchers W, Verweij PE, CuencaEstrella M, Rodríguez-Tudela JL. A new Aspergillus fumigatus resistance mechanism conferring in-vitro cross-resistance to azole antifungals involves a combination of cyp51A alterations. Antimicrob Agents Chemother. 2007; 51(6):1897-904.

37. Mowat E, Lang S, Williams C, McCulloch E, Jones B, Ramage G. Phasedependent antifungal activity against Aspergillus fumigatus developing multicellular filamentous biofilms. J Antimicrob Chemother. 2008;62(6): $1281-4$.

38. Verweij PE, Zhang J, Debets AJM, Meis JF, Schoustra SE, van de Veerdonk FL, Zwaan BJ, Melchers WJG. In-host adaptation and acquired triazole resistance in Aspergillus fumigatus: a dilemma for clinical management. Lancet Infect Dis. 2016;16(11):e260.

39. Ballad E, Melchers W, Zoll J, Brown A, Verweij PE, Warris A. In-host microevolution of Aspergillus fumigatus: a phenotypic and genotypic analysis. Fungal Genet Biol. 2018;113:1.

40. Paisley D, Robson GD, Denning DW. Correlation between in vitro growth rate and in vivo virulence in Aspergillus fumigatus. Med Mycol. 2005;43(5): 397-401.

41. Peeters D, Day MJ, Clercx C. An immunohistochemical study of canine nasal aspergillosis. J Comp Pathol. 2005;132(4):283-8.

42. de Valk HA, Meis JF, de Pauw BE, Donnelly PJ, Klaassen CH. Comparison of two highly discriminatory molecular fingerprinting assays for analysis of multiple Aspergillus fumigatus isolates from patients with invasive aspergillosis. J Clin Microbiol. 2007;45(5):1415-9.

43. Howard SJ, Pasqualotto AC, Anderson MJ, Leatherbarrow H, Albarrag AM, Harrison E, Gregson L, Bowyer P, Denning DW. Major variations in Aspergillus fumigatus arising within aspergillomas in chronic pulmonary aspergillosis. Mycoses. 2013;56(4):434-41.

44. Escribano P, Peláez T, Bouza E, Guinea J. Microsatellite (STRAf) genotyping cannot differentiate between invasive and colonizing Aspergillus fumigatus isolates. J Clin Microbiol. 2015;53(2):667-70.

45. Verweij PE, Chowdhary A, Melchers WJ, Meis JF. Azole resistance in Aspergillus fumigatus: can we retain the clinical use of mold-active antifungal azoles? Clin Infect Dis. 2016;62(3):362-8.

46. van Ingen J, van der Lee HA, Rijs TA, Zoll GJ, Leenstra T, Melchers WJG, Verweij PE. Azole, polyene and echinocandin MIC distributions for wild-type, TR34/L98H and TR46/Y121F/T289A Aspergillus fumigatus isolates in the Netherlands. J Antimicrob Chemother. 2015;70(1):178-81.

47. Jensen RH, Hagen F, Astvad KMT, Tyron A, Meis JF, Arendrup MC. Azoleresistant Aspergillus fumigatus in Denmark: a laboratory-based study on resistance mechanisms and genotypes. Clin Microbiol Infect. 2016;22(6): 570.e9.

48. Klaassen CH, Gibbons JG, Fedorova ND, Meis JFGM, Rokas A. Evidence for genetic differentiation and variable recombination rates among Dutch populations of the opportunistic human pathogen Aspergillus fumigatus. Mol Ecol. 2012:21(1):57-70.

49. Chowdhary A, Meis JF. Emergence of azole resistant Aspergillus fumigatus and one health: time to implement environmental stewardship. Environ Microbiol. 2018:20:1299.

50. Abdolrasouli A, Rhodes J, Beale MA, Hagen F, Rogers TR, Chowdhary A, Meis JF, Armstrong-James D, Fisher MC. Genomic context of azole resistance mutations in Aspergillus fumigatus determined using whole-genome sequencing. MBio. 2015;6(3):536.

51. de Aldana CR, Vazquez LA, Fraser C, Lu C, Fosker N, Tekaia F, Saunders D, Kitamoto K, Murphy L, Haas B, Lafton A, Bennett J, Fischer R, Huang J, Barrell B, Fraser A, Molina M, Sanchez M, O'Neil S, Feldblyum TV, García MJ, Woodward J, Keller N, Pain A, García JL, Price C, Rawlins N, Yu J, Goldman GH, Quail MA, Kumagai T, Berriman M, Renauld H, Asai K, Mohamoud Y, Konzack S, Machida M, Hall N, Collins M, Majoros WH, Kulkarni R, Mulligan S, Robson GD, Jiménez J, Arroyo J, Horiuchi H, Ronning CM, Gomi K, Pertea M, Coulsen R, Harris D, Fedorova N, White O, Haas H, Turner G, Paulsen I, Galagan JE, Archer DB, Griffith-Jones S, Denning DW, Miller BL, SánchezFerrero JC, Seeger K, Chen D, May GS, Gwilliam R, Goble A, Monod M, Abe K, Takeuchi M, Peñalva MA, Kobayashi T, Fedorova N, Farman M, Li W, Kim HS, Nierman WC, Weidman J, Pritchard BL, Mouyna I, Bowyer P, Squares S, Khouri H, de Córdoba SR, Davies R, Dyer PS, Latgé J, Bermejo C, RodríguezPeña JM, Rutter S, Wortman JR, Humphray S, Rabbinowitsch E, Squares R, Anderson MJ, Reichard U, Salzberg SL, Rajandream M. Genomic sequence of the pathogenic and allergenic filamentous fungus Aspergillus fumigatus. Nature. 2005:438(7071):1151-6.

52. Fedorova ND, Khaldi N, Joardar VS, Maiti R, Amedeo P, Anderson MJ, Crabtree J, Silva JC, Badger JH, Albarraq A, Angiuoli S, Bussey H, Bowyer P, Cotty PJ, Dyer PS, Egan A, Galens K, Fraser-Liggett CM, Haas BJ, Inman JM, 
Kent R, Lemieux S, Malavazi I, Orvis J, Roemer T, Ronning CM, Sundaram JP, Sutton G, Turner G, Venter JC, White OR, Whitty BR, Youngman P, Wolfe KH, Goldman GH, Wortman JR, Jiang B, Denning DW, Nierman WC. Genomic islands in the pathogenic filamentous fungus Aspergillus fumigatus. PLoS Genet. 2008:4(4):e1000046.

53. Hong S, Go S, Shin H, Frisvad JC, Samson RA. Polyphasic taxonomy of Aspergillus fumigatus and related species. Mycologia. 2005;97(6):1316-29.

54. Glass NL, Donaldson GC. Development of primer sets designed for use with the PCR to amplify conserved genes from filamentous ascomycetes. Appl Environ Microbiol. 1995;61(4):1323-30

- fast, convenient online submission

- thorough peer review by experienced researchers in your field

- rapid publication on acceptance

- support for research data, including large and complex data types

- gold Open Access which fosters wider collaboration and increased citations

- maximum visibility for your research: over $100 \mathrm{M}$ website views per year

At $\mathrm{BMC}$, research is always in progress.

Learn more biomedcentral.com/submissions 